\title{
Evaluation of methylparaben removal and microbial behavior using a SBR system
}

\author{
Remoción de methilparabeno y comportamiento microbiano de un sistema SBR
}

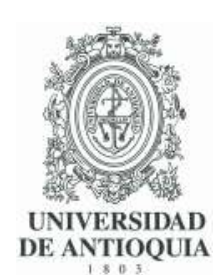

\author{
Eduar Andres Isaza Botero (D) ${ }^{1}$, Yudy Andrea Londoño (iD ${ }^{1}$, Nancy J. Pino (D) ${ }^{2 *}$, Gustavo A. Peñuela (D) ${ }^{1}$ \\ ${ }^{1}$ Grupo GDCON, Facultad de Ingeniería, Sede de Investigación Universitaria (SIU), Universidad de Antioquia. Calle 70 \# 52 -21. C. P. \\ 050010. Medellín, Colombia. \\ ${ }^{2}$ Escuela de Microbiología, Universidad de Antioquia. Calle 70 \# 52-21. C. P. 050010. Medellín, Colombia.
}

\section{CITE THIS ARTICLE AS:}

E. A. Isaza, Y. A. Londoño, N. J. Pino, G. A. Peñuela.

"Evaluation of methylparaben removal and microbial behavior using a SBR system", Revista Facultad de Ingeniería Universidad de Antioquia, 92, pp. 80-87, Jul-Sep 2019. [Online]. Available: https://www . doi.org/10.17533/ udea.redin. 20190626

\section{ARTICLE INF0:}

Received: February 19, 2019

Accepted: June 14, 2019 Available online: June 14, 2019

\section{KEYWORDS:}

Water treatment, water pollution, microbial populations

Tratamiento de aguas, contaminación del agua, poblaciones microbianas
ABSTRACT: We evaluated the variation in microbial populations and the behavior of an SBR system in the removal of methylparaben (MePB). The experimentation was carried out for 14 weeks, in three operational stages as follows: stabilization (Stage I), (Stage II $=300$ $\mu \mathrm{gMePB} / \mathrm{L}$ and Stage $\mathrm{III}=600 \mu \mathrm{gMePB} / \mathrm{L}$ ). The variation of the microorganisms was analyzed over the experimentation time along with the contact with the pollutant to be degraded, and the removal percentage of $\mathrm{COD}$ and MePB, with results of $88 \pm 5,5 \%$ and $92 \pm 7,7 \%$ respectively. Kinetic of MePB removal was evaluated to obtain the rate constant of biological degradation, $K_{\text {biol }}$. Using these kinetic results, the effect of different concentrations of MePB and biomass on biodegradation behavior was evaluated. $\mathrm{K}_{\text {biol }}\left(\mathrm{LgSS}^{-1} \mathrm{~d}^{-1}\right)$ values were obtained of 42.8 and 79 respectively; and $472 \pm 38.0 \mu \mathrm{gMePB} / \mathrm{L}$, at biomass contents of 1466.7 and $2666.7 \mathrm{mgSSV} / \mathrm{L}$, where $\mathrm{K}_{\text {biol }}\left(\mathrm{LgSS}^{-1} \mathrm{~d}^{-1}\right)$ values were obtained of 11.0 and 32.6 respectively.

The variation of the microbial populations were analyzed using DGGE. The results obtained indicated that the populations presented similar characteristics between the stages. However, for the biomass samples of Stage I and stage III, significant differences were identified in the composition of microbial populations. Nonetheless, this did not affect the removal of MePB and the diversity conditions that characterize an aerobic system.

RESUMEN: Se evaluó la variación en las poblaciones microbianas y el comportamiento de un sistema SBR en la eliminación de metilparabeno (MePB). La experimentación se llevó a cabo en tres etapas: (Etapa I: aclimatacion), (Etapa II $=300 \mu \mathrm{gMePB} / \mathrm{L}$ y Etapa III $=600 \mu \mathrm{gMePB}$ / L). La variación de los microorganismos se analizó durante el tiempo de experimentación junto con el contacto con MePB y el porcentaje de eliminación de DQO, con resultados de $88 \pm 5,5 \%$ y $92 \pm 7,7 \%$ respectivamente. Se evaluó la eliminación cinética de MePB para obtener la constante de velocidad de degradación biológica, $\mathrm{K}_{\text {biol. }}$. Usando estos resultados cinéticos, se evaluó el efecto de diferentes concentraciones de MePB y biomasa en el comportamiento de la biodegradación. Se obtuvieron valores de $\mathrm{K}_{\text {biol }}\left(\mathrm{LgSS}^{-1} \mathrm{~d}^{-1}\right)$ de 42.8 y 79 respectivamente; y $472 \pm 38.0 \mu \mathrm{gMePB} / \mathrm{L}$, a contenidos de biomasa de 1466.7 y 2666.7 mgSSV / L, donde se obtuvieron valores de $K_{\text {biol }}\left(\mathrm{LgSS}^{-1} \mathrm{~d}^{-1}\right)$ de 11.0 y 32.6 respectivamente. La variación de las poblaciones microbianas se analizó utilizando DGGE. Los resultados indicaron que las poblaciones presentaron características similares entre las etapas, pero para las muestras de biomasa de Etapa I y Etapa III, se identificaron diferencias significativas en la composición de las poblaciones microbianas. No obstante, esto no afectó la eliminación de MePB y las condiciones de diversidad que caracterizan a un sistema aeróbico.

\section{Introduction}

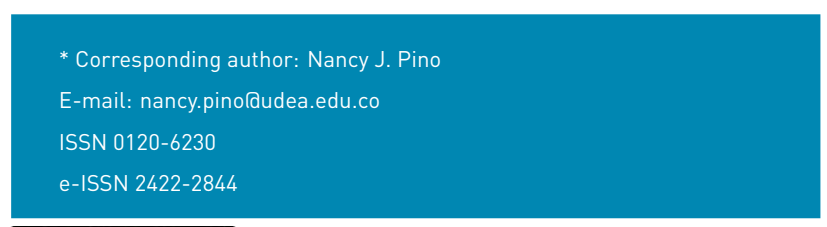

Emerging contaminants can be present in different environmental compartments in concentrations ranging from $\mathrm{ng} / \mathrm{L}$ to $\mu \mathrm{g} / \mathrm{L}[1]$. Many of these pollutants are components of commercial products that are used 
daily in domestic and industrial settings, including pharmaceutical products and personal care products [PPCPs) [2]. It is estimated that these substances, although found in low concentrations in the environment, could produce environmental impacts due to their frequent use, persistence and the risk they pose to aquatic life and humans [3].

One group of such emerging pollutants are parabens, which include Methylparaben (MePB), Ethylparaben (EtPB), Propylparaben (PrPB) and Butylparaben (BrPB) [4], which are widely used alone or combined in everyday products such as cosmetics or personal care products. They are used to retard the growth of fungi and bacteria through their fungicidal and antimicrobial properties [5]. Parabens have received increasing attention due to their possible long-term effects on human health and aquatic organisms [6]. Concentrations of MePB detected in wastewater treatment plants (WWTP) can be significant, with levels up to $80 \mu \mathrm{g} / \mathrm{L}$ being found in tributaries [4]. Due to their wide and continuous use parabens can enter the environment via domestic and industrial wastewater. [6]. As conventional wastewater treatment plants have not been designed to treat this type of pollutant [1], there is a high probability that these compounds reach the natural environment without being removed to a significant degree. For this reason, the development and optimization of physicochemical and biological treatment technologies that can solve this problem and ensure the safety of residual effluents has been evaluated in recent years. Among these technologies, biological systems lanaerobic and aerobic) are of great attractiveness because they can achieve high efficiencies at a low cost of operation. The Sequencing Batch Reactor (SBR) is a promising aerobic based technology due to its high efficiencies and great operational versatility, which has been used both for the removal of organic matter and nutrients.

Some studies have reported that micropollutants such as parabens were $99 \%$ biodegraded in less than 5 days [4], while [1], recorded MePB removal percentages greater than $97 \%$. However, it is not yet clear if there are alterations in the operation of SBR system due to changes caused to the populations of microorganisms in contact with the micropollutant. Changes in the microbiota of the reactor could be associated with the prevalence of a certain group of microorganisms or with a change in the structure of the microbial populations, which could alter the dynamics of response and / or performance of the reactor against fluctuations in the treatment affluent. For this reason, this study evaluated the removal process of MePB present in a synthetic wastewater at different levels of concentration through the application of aerobic biological processes, in order to determine the effect of this pollutant on the behavior and evolution of microbial populations responsible for the removal of MePB and COD.

\section{Materials and methods}

\subsection{Description of the SBR reactor}

The experimental test was carried out at the GDCON group with an existing SBR system at laboratory scale, manufactured in acrylic, with a height of $70 \mathrm{~cm}$ and internal diameter of $15 \mathrm{~cm}$. The phases of the reactor were automated by "batch" with a PLC (Programmable Logic Control) system developed by [7], which allows versatility and flexibility in the operation. The system, shown in Figure 1, has a mechanical agitator, peristaltic pump, six submerged air diffusers, and their respective valves.

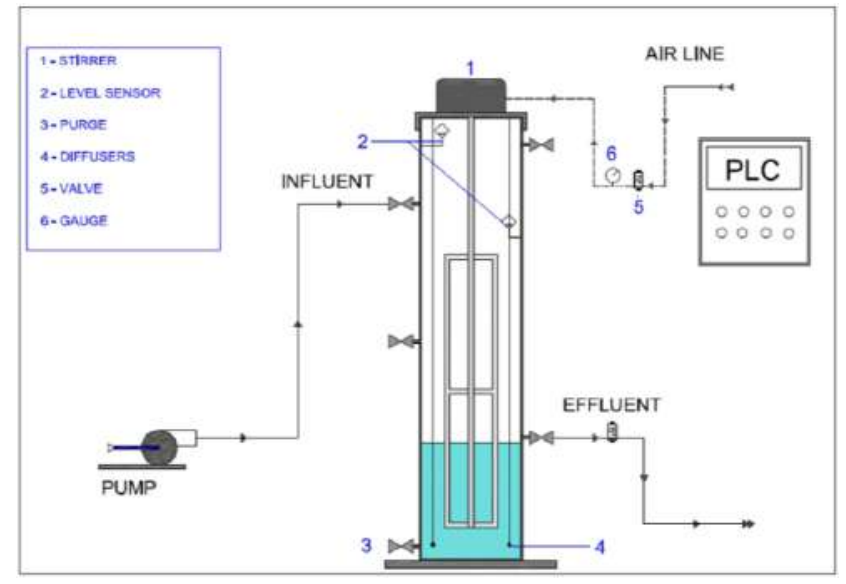

Figure 1 SBR reactor scheme [1]

\subsection{Inoculum}

The sludge used to inoculate the reactor was taken from the wastewater treatment plant (WWTP) of the recreational park "Parque los Tamarindos", where an industrial-scale SBR system is used to treat waste mainly of domestic and recreational characteristics. The sludge has a concentration of total suspended solids (TSS) of $7220 \pm$ $66.6 \mathrm{mg} / \mathrm{L}$, a concentration of volatile suspended solids (VSS) of $4945 \pm 6.1 \mathrm{mg} / \mathrm{L}$, and a sedimentation rate of 2 . $12 \pm 0.01 \mathrm{~m} / \mathrm{h}$.

\subsection{Operational strategy}

The operation of the SBR system was distributed over 14 weeks in three operation stages, which included stabilization and startup (Stage I), and the variation of the concentration of the study pollutant (Stage $\|=300$ $\mu \mathrm{gMePB} / \mathrm{L}$ and Stage $\mathrm{III}=600 \mu \mathrm{gMePB} / \mathrm{L})$. Figure 2 shows the operation stages: 


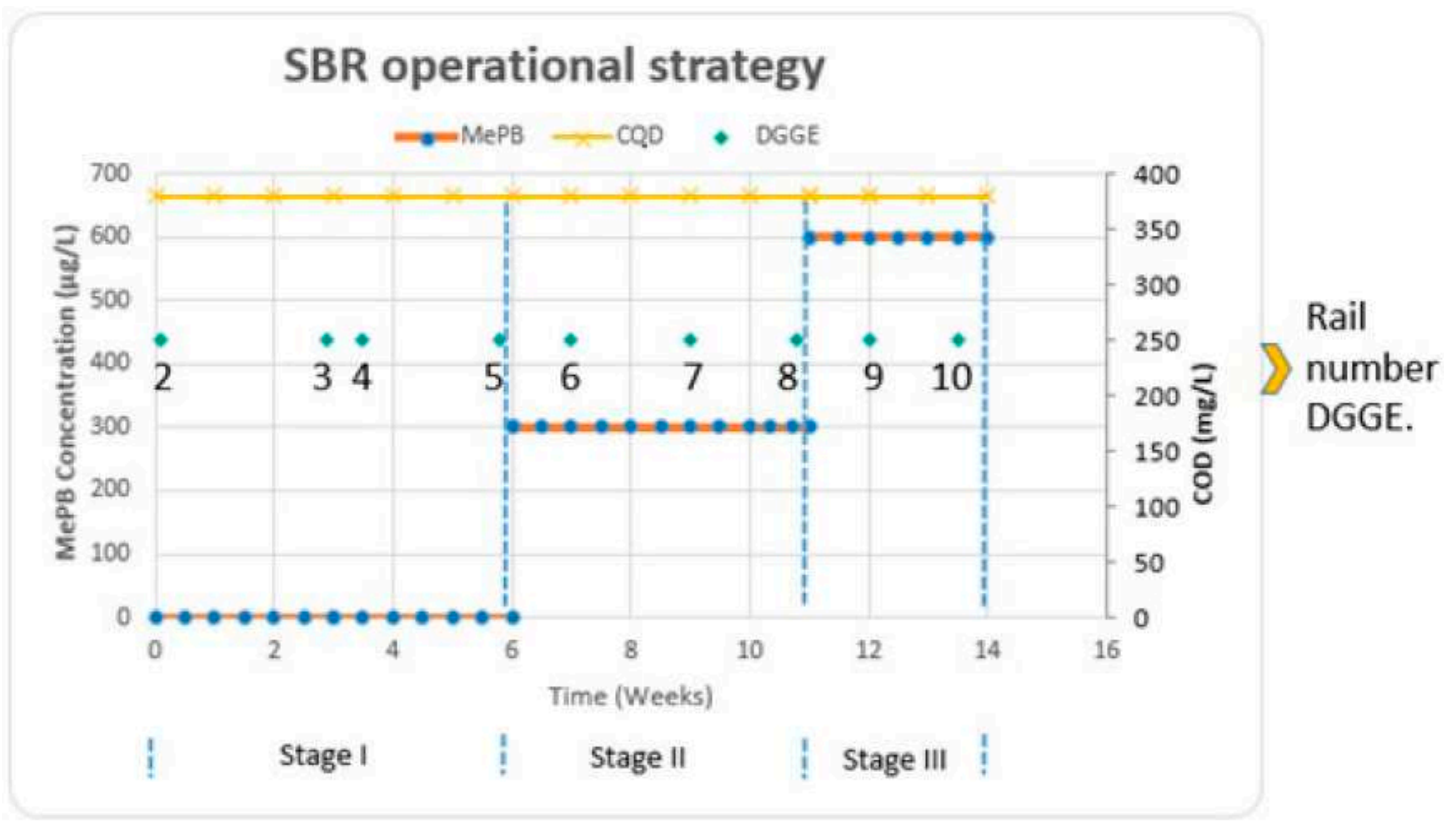

Figure 2 SBR operational strategy

Figure 2 specifies the moments for each stage in which samples were taken for DGGE molecular microbiology analyzes, usually at the beginning and end of the stage. The number that represents each point determines the vertical band showing the result in the DGGE photograph.

The COD concentration contributed by glucose remained constant throughout the experimentation. The hydraulic retention time was 8 hours, with a high sludge age of around 12 days, and F/M ratio (food/microorganisms) approximately ranging between $0.7-0.9$. Each cycle was made up of the phases described in Table 1.

Table 1 Description of the phases that make up an SBR system operation cycle

\begin{tabular}{lll}
\hline Phase & Time $(h)$ & Operational Conditions \\
\hline Fill & 2.7 & Agitation + Aeration \\
\hline Reaction & 2.0 & Agitation + Aeration \\
\hline Sedimentation & 2.6 & Inactivity \\
\hline Emptying & 0.7 & Emptying - Inactivity \\
\hline
\end{tabular}

\subsection{Composition of synthetic wastewater}

For the reactor operation, wastewater was prepared in the laboratory according to the minimum requirements of the metabolism of the microorganisms, taking into account macro and micro nutrient solutions as reported by [8] and the COD: N: P ratio. of 100: 5: 1 reported by [1]. The main source of added carbon was industrial glucose and, to avoid its rapid degradation in the environment and the acidification of the mixing liquor, industrial sodium bicarbonate $\left(\mathrm{NaHCO}_{3}\right)$ was added in a 2:1 ratio of glucose and bicarbonate, respectively. Additionally, the pollutant was added to the solution in accordance with the stage of operation.

\subsection{MePB degradation kinetics tests}

The degradation kinetics tests of MePB were carried out in $2 \mathrm{~L}$ containers with continuous aeration systems that guaranteed complete mixing. The biomass was inoculated with micro and macronutrient solutions according to the dilution water conditions of the BOD5 method [9]. Additionally, glucose was used as co-substrate in a COD concentration of $250 \mathrm{mgO}_{2} / \mathrm{L}$.

Experimentation of MePB degradation was carried out at two pollutant concentrations. The first, of 179 $\pm 38 \mu \mathrm{gMePB} / \mathrm{L}$, was established in two biomass concentrations with values of 1450 and $2016 \mathrm{mgSSV} / \mathrm{L}$. The second concentration, of $472 \pm 38 \mu \mathrm{gMePB} / \mathrm{L}$, was degraded at biomass concentrations of 1467 and 2667 $\mathrm{mgSSV} / \mathrm{L}$. The MePB was tracked with periodic sampling to determine the kinetic degradation constant, $\mathrm{K}_{\mathrm{Biol}}$, according to a pseudo-first-order reaction [10].

\subsection{Calculation of $\mathbf{K}_{\text {biol }}$}

The degradation of the MePB was calculated from the biodegradation constant, $\mathrm{K}_{\mathrm{Biol}}$, following a pseudo-first order kinetic $[10,11]$ according to the Equation 1:

$$
\frac{d C}{d t}=k_{b i o l} X_{S S} S
$$


Where $\mathrm{C}$ is the total concentration of compound $(\mu \mathrm{g} / \mathrm{L}), \mathrm{S}$ the concentration of soluble compound $(\mu \mathrm{g} / \mathrm{L}), \mathrm{t}$ time (d), $\mathrm{K}_{\text {biol }}$ the rate of reaction constant $\left(\mathrm{Lg}^{-1} \mathrm{SSd}^{-1}\right)$ and XSS the suspension of solids (gSSL ${ }^{-1}$ ) [12] .

\subsection{Analytical methods}

Monitoring of control and response variables, such as chemical oxygen demand (COD), dissolved organic carbon (DOC), dissolved oxygen, $\mathrm{pH}$, oxide-reduction potential (ORP), volatile suspended solids (VSS), total suspended solids (TSS) and the volumetric sludge index (IVL) were performed in the GDCON laboratory of the University of Antioquia, according to the methodologies established by Standard Methods [9]. This laboratory has IDEAM accreditation (Institute of Environmental Studies of the Ministry of Environment of Colombial for the analysis of these parameters.

The quantification of MePB was performed by liquid chromatography coupled to a mass spectrometry detector using ACQUITY UPLC H-Class equipment (Triple quadruple) coupled to a XEVO TQD mass spectrometer, through an internal method developed in the GDCON laboratory of the University of Antioquia.

The variation of the prokaryotic community in the SBR system was evaluated using the molecular technique Electrophoresis in Denaturing Gradient Gel (DGGE). Samples were collected once a week from the mixing liquor as follows: $100 \mathrm{~mL}$ of liquor was centrifuged at 6,000 rpm for 5 minutes (Eppendorf Centrifuge 5810R), the supernatant was discarded, and the pellet then maintained in Eppendorf tubes at $-20^{\circ} \mathrm{C}$ until the time of analysis, at the end of the experiment. Only the representative samples were analyzed, usually at the beginning and end of each stage of operation. DNA extraction was performed with the commercial kit E.Z.N.A ${ }^{\circledR}$ Soil DNA (Omega bio-tek, USA) according to the manufacturer's instructions.

For the DGGE analysis, the DNAr 16S fragments corresponding to nucleotide positions 341 - 534 in the $E$. coli sequence were amplified using the $341 \mathrm{fGC}$ primers with "the GC clamp of 40 base at the $5^{\text {" end }}$ and the reverse primer 518r. The Taq DNA polymerase (Thermo, Scientific \#EP0402) kit was used for PCR. Each PCR reaction contained $25 \mu \mathrm{L}$ of the mix composed of: $2.5 \mu \mathrm{L}$ of Taq Buffer 10X, $1.5 \mu \mathrm{L}$ of $\mathrm{MgCl} 225 \mathrm{mM}, 0.5$ $\mu \mathrm{L}$ of dNTPs (final concentration $200 \mu \mathrm{M}$ ), $0.5 \mu \mathrm{L}$ for each primer (final concentration, $0.2 \mu \mathrm{M}$ ), $0.1 \mu \mathrm{L}$ of Taq polymerase ( $0.5 \mathrm{U} / 25 \mu \mathrm{L}$ of reaction), $2.5 \mu \mathrm{L}$ of $1 \%$ bovine serum albumin, $3 \mu \mathrm{L}$ of DNA ( $20 \mathrm{ng}$ ) and $13.9 \mu \mathrm{L}$ of water.

The reaction was performed in a TM100TM thermal cycler (Bio-Rad, USA). The PCR was performed according to [13], with the following modifications: the annealing temperature at $65^{\circ} \mathrm{C}$ decreased $1^{\circ} \mathrm{C}$ per cycle instead of every two cycles, and 20 additional cycles were run at $55^{\circ} \mathrm{C}$. The DGGE was performed at $6 \%(\mathrm{P} / \mathrm{V})$ of polyacrylamide (Acryl/BisTM,37.5:1, AMRESCO ${ }^{\circ}$, USA), in a TAE $1 \mathrm{X}$ buffer, at a temperature of $60^{\circ} \mathrm{C}$, for 500 minutes, at a power of $110 \mathrm{~V}$. The buffer contained a denaturing gradient of $30-70 \%$ urea and formamide $1100 \%$ Urea $7 \mathrm{M}$ and $40 \%$ formamide (P/V)). After electrophoresis, the gel was stained with Sybr ${ }^{\circledR}$ Green 1 X (Lonza, USA) at TAE 1 X for 30 minutes, before visualization (Labnet, EnduroTM GDS). The gel image was captured on an ENDURO GDS Touch gel documentation system (EnduroTM Labnet, USA) under UV light. DGGE banding patterns were analyzed using GEL COMPAR II (Applied Maths, Ghent, Belgium) software. The similarity matrix was calculated using the Pearson's correlation coefficient. Cluster analysis was performed using the unweighted pair group method with an arithmetic average (UPGMA). Similarity analysis was used to examine the significant statistical differences between the DGGE profiles and the results were finally presented as a dendrogram.

\section{Results and discussion}

\subsection{Degradation kinetics}

The degradation kinetics constant, $\mathrm{K}_{\mathrm{Biol}}\left(\mathrm{LgSS}^{-1} \mathrm{~d}^{-1}\right)$, based on a pseudo-first-order reaction, is used to describe the exponential degradation of the contaminant with the concentration of suspended solids of the mixing liquor (mgVSS/L) [10]. Under this model, the results of MePB degradation are shown in Table 2.

The results of the degradation kinetics of MePB showed an important effect of the biomass and initial micropollutant concentration on the pollutant degradation speed. This behavior can be observed in Table 2; when the MePB concentration is increased and biomass concentration remains similar, the degradation rate decreases markedly. The degradation constant $\left(\mathrm{K}_{\text {biol }}\right)$ for the average biomass concentration of $1458 \mathrm{mgVSS} / \mathrm{L}$ presents values of 42.3 and $11.0 \mathrm{Lgss}^{-1} \mathrm{~d}^{-1}$ for MePB concentrations of 179 and $472 \mu \mathrm{g} / \mathrm{L}$, respectively. This indicates that when the concentration of MePB increased from $179 \mu \mathrm{g} / \mathrm{L}$ to 472 $\mu \mathrm{g} / \mathrm{L}$, the degradation rate of the compound decreased by the order of 3.8 times, based on the value of the constant obtained for the lowest concentration of the contaminant (179 $\mu \mathrm{g} / \mathrm{L}$ ). This behavior is seen to be repeated for the average biomass concentration of $2342 \mathrm{mgVSS} / \mathrm{L}$ when the two MePB concentrations are evaluated.

On the other hand, when analyzing the variation in $\mathrm{K}_{\mathrm{biol}}$ for each concentration of the micropollutant, it was evidenced that when the concentration of the biomass 
Table 2 Results of the MePB degradation test

\begin{tabular}{|c|c|c|c|}
\hline \multicolumn{2}{|c|}{ MePB $_{1}=179 \pm 38 \mu \mathrm{gMePB} / \mathrm{L}$} & \multicolumn{2}{|c|}{$\mathrm{MePB}_{2}=472 \pm 38 \mu \mathrm{gMePB} / \mathrm{L}$} \\
\hline VSS (mg/L) & $K_{\text {Biol }}\left(\operatorname{Lgss}^{-1} d^{-1}\right)$ & SSV (mg/L) & $K_{\text {Biol }}\left(\operatorname{Lgss}^{-1} d^{-1}\right)$ \\
\hline 1450 & 42.8 & 1467 & 11.0 \\
\hline 2016 & 79.4 & 2667 & 32.6 \\
\hline
\end{tabular}

increases, these values also increase significantly. In the case of the concentration of $179 \mu \mathrm{g} / \mathrm{L}$ of MePB, $\mathrm{K}_{\mathrm{biol}}$ values were obtained of of 42.8 and 79.40 Lgss $_{-1} \mathrm{~d}_{-1}$ for VSS values of 1450 and $2016 \mathrm{mg} / \mathrm{L}$, respectively. This indicates a favorable effect of increasing the sludge concentration on the degradation rate of MePB. This trend has been reported in other studies, in which it is indicated that there is a directly proportional relationship between the biomass concentration and the increase in the degradation rate of organic micropollutants. [10].

The values of the biodegradation constant $\left(\mathrm{K}_{\mathrm{biol}}\right)$ have been reported in a range that varies from 0.72 to 17.44 L.gSST ${ }^{-1} \cdot d^{-1}$ [14]. Values in this range that are above $10 \mathrm{~L} . \mathrm{gSST}^{-1} \cdot \mathrm{d}^{-1}$ present high biodegradation [1]. This indicates that the values of the degradation constants obtained during the experimentation are the result of high biodegradation of the MePB in the test conditions. However, the variation between these $K_{\text {biol }}$ values is explained by the concentration of the biomass, as well as by the initial concentration of the microcontaminant.

\subsection{Analytical follow-up of the SBR}

The operation of the SBR system begins with a period of acclimatization of the sludge to the new hydraulic and environmental conditions in the reactor. This aims for the adaptation of the microorganisms to the synthetic wastewater, taking into account that the microorganisms were previously in other conditions, of WWTP origin. The synthetic wastewater prepared for the experiment had a TKN level of $21.840 \mathrm{mgN} / \mathrm{L}$ and a phosphorus level of $5.78 \mathrm{mgP} / \mathrm{L}$, meeting the minimum requirements for the metabolism of microorganisms according to the COD ratio: $\mathrm{N}$ : P of 100: 5: 1, recommended for aerobic processes by [8].

The inoculation sludge was recovered directly from the purification line of the WWTP of the recreational park Parque los Tamarindos, which had a total suspended solids concentration (TSS) of $5580 \mathrm{mgSST} / \mathrm{L}$, of volatile suspended solids (VSS) concentration of $5020 \mathrm{mgVSS} / \mathrm{L}$, and an adequate sedimentation rate, evidenced in the clarification of treated water.

The dissolved oxygen concentration of the mixture liquor under normal operating conditions ranged between approximately 4 and $5 \mathrm{mgO}_{2} / \mathrm{L}$. These values indicate that an adequate supply of DO for the oxidation process of the organic matter and to satisfy the demand of the microbial mass was present, with a residual above $2 \mathrm{mgO}_{2} / \mathrm{L}$ being maintained [1].

The behavior of the $\mathrm{pH}$ during the experimentation was very stable, presenting values with a tendency to neutrality, between 6.5 and 8.5 . These values are reported by [1], for the optimal performance of the aerobic biomass.

COD analyzes were performed to evaluate the removal percentage of organic matter during the experimental phase, the results of which are shown in Figure 3.

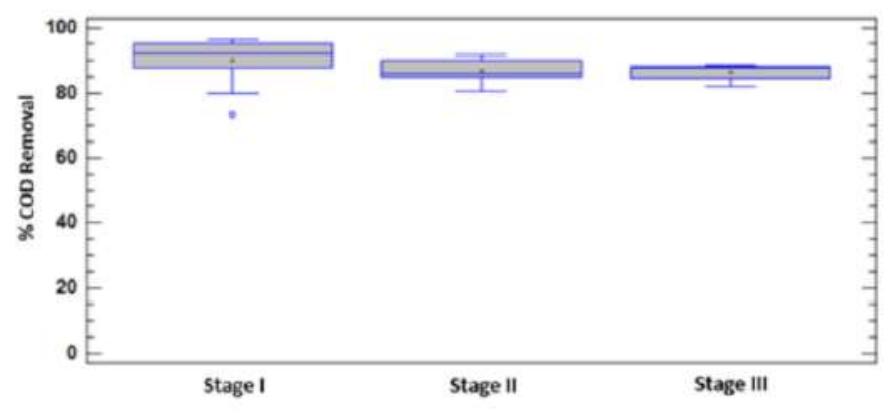

Figure 3 Behavior of COD removal by Stages

The maximum values of organic matter removal by COD in Stage I were greater than 96\%. Such values are comparable with other suspended biomass SBR systems that can remove organic contaminants relatively well in terms of carbon removal (C). Thus, some studies report eliminations of more than $90 \%$ in Biochemical Oxygen Demand (BOD) [15].

The maximum values of COD removal in the experiment occur when a steady state is achieved in the biological system and a sludge age is reached with an optimum F/M ratio. However, during the experimental period this cell retention time showed small variations, which implied changes in the quality of the effluent and sedimentation of the sludge. Even so, COD removal percentages higher than $80 \%$ were obtained throughout the experimentation.

During Stage II, a decrease and recovery was observed in the removal of COD corresponding to contact with the first load of the pollutant. The removal behavior of MePB in Stage II showed an increase (Figure 4); probably while the adaptation of the microorganisms to the contaminant to a 
new source of carbon for its metabolic functions occurs.

Removal percentages at all the stages of experimentation show no statistically significant differences. Even so, the small variations between stages can probably be associated with slight changes of in the microbial populations in the system, due to operational conditions or the impact of the pollutant itself.

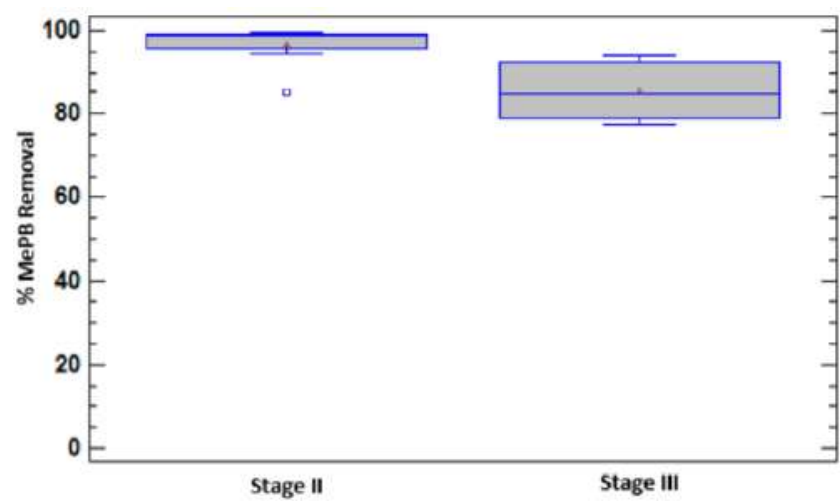

Figure 4 Behavior in MePB removal

The results of MePB quantification allow the determination that the percentages of elimination of the contaminant are statistically different at the various stages, due to removal variations in time, which is probably caused by alterations in the microbial populations of the system in contact with the MePB or in the operating conditions.

Parabens have been described as easily biodegradable under aerobic conditions, such as in the case of biodegradation using activated sludge [4]. At Stage II the MePB removal percentages are greater than $95 \%$. These results of high efficiency are comparable with those reported by [1]. Additionally, high parabens removal percentages with biological treatment systems have been reported (96.1 to $99.9 \%$ ), but these pollutants persist in effluents at concentrations up to approximately $4 \mu \mathrm{g} / \mathrm{L}$ [4]. At Stage III, a change in the MePB removal percentage of $85.5 \pm 7,6 \%$ is clearly observed. A marked effect on the system of increasing the pollutant concentration can be inferred. However, as time passes, the microorganisms increasingly tolerate the conditions of the pollutant in their environment and achieve removal percentages close to $90 \%$

The high removal rates of the microcontaminant are clear because MePB has shown almost complete biodegradation (99\%) in less than 5 days, with a half-lie of no more than 3 days. This indicates that it is biodegraded in its entirety and that abiotic effects such as sorption are not relevant [4].

The sludge volumetric index (IVL) and biomass concentration, represented by $\mathrm{mgVSS} / \mathrm{L}$, is shown in Table 3 for each stage.

Table 3 Results of biomass characterization for each stage of SBR operation

\begin{tabular}{lllll}
\hline Stage & $\begin{array}{l}\text { VSSV } \\
\text { (mg/L) }\end{array}$ & $\begin{array}{l}\text { TSS } \\
\text { (mg/L) }\end{array}$ & $\begin{array}{l}\text { IVL } \\
\text { (mL/g) }\end{array}$ & $\begin{array}{l}\text { Degree of } \\
\text { sedimentation }\end{array}$ \\
\hline Stage I & 2320 & 2460 & 150.4 & Appropriate \\
\hline Stage II & 2140 & 2260 & 185.8 & Appropriate \\
\hline Stage III & 1790 & 1890 & 291.0 & Meager \\
\hline
\end{tabular}

Monitoring of the IVL and the concentration of solids was carried out at the end of each stage. In general, a tendency to lose biomass between stages was observed, influenced by the decrease of the degree of sedimentation, which is due to the operational conditions such as the optimization of the sludge age. It is not possible to state that MePB is the cause of this.

\subsection{Analysis of bacterial changes}

The sludge samples analyzed with DGGE are specified in Figure 5, and correspond to the most representative of each stage of experimentation. These are: for Stage I Lanes $(2,3,4,5)$; Stage II $(6,7,8)$; and Stage III $(9,10)$. In the DGGE image in Figure 5, the results of the molecular tests for each sample, represented by vertical rails or bands, can be observed.

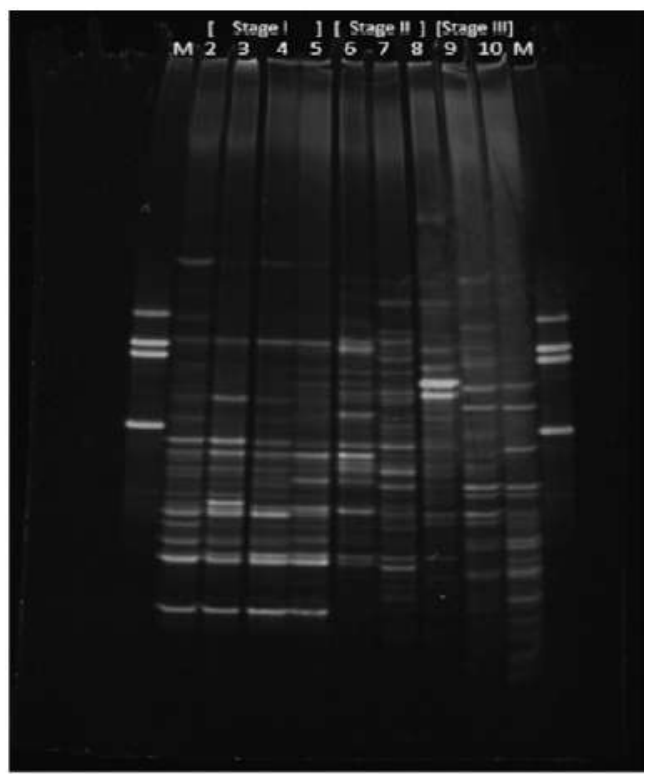

Figure 5 Photograph obtained from DGGE for the biomass of the SBR system at the different stages of operation

The lanes named as (M) in Figure 5 correspond to test markers or controls. These are presented as two identical profiles and must give a percentage of similarity of $100 \%$, 


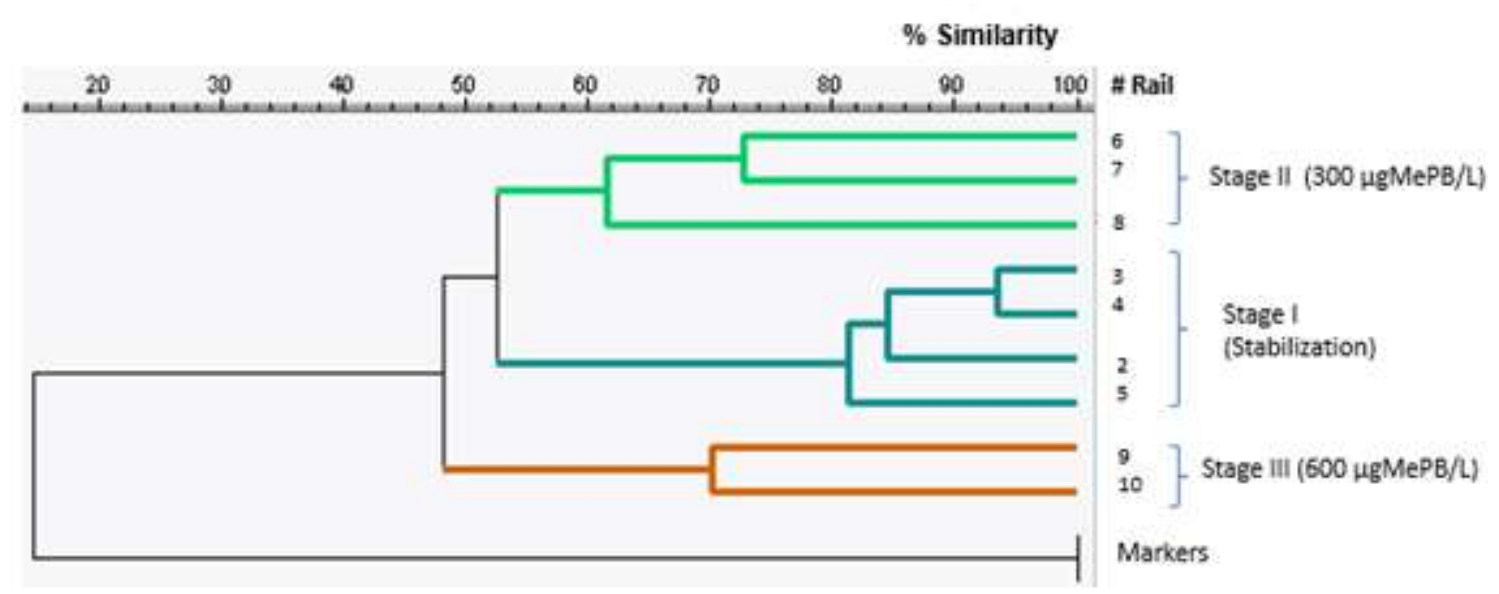

Figure 6 Dendrogram of Molecular Microbiology samples

which marks a noticeable difference between the other bands and a relevant similarity between them.

At first sight, the results of the DGGE show profiles with highly diverse denatured fragments at all stages. Depending on the intensity of the band, it can be inferred that there is a greater population can be inferred at some moments than others. Although the banding pattern cannot indicate abundance, since DGGE is a qualitative test, high richness can be stated to be present throughout the experimentation, including at the highest concentration of MePB, which is characteristic of aerobic sludge. This may indicate that the microorganisms analyzed by DGGE did not suffer a very marked effect from the presence of MePB in their environment.

It is interesting to note that MePB, an antimicrobial compound, does not generate significant variability in the microbial populations represented by the $16 \mathrm{~S}$ rDNA fragment, and how the aerobic biomass maintains high diversity characteristics throughout the time experimentation, in contrast to the high removal values of MePB during Stage II and Stage III.

The results shown in the dendrogram in Figure 6 correspond to three main clusters, which group the samples in stages. The similarity percentage between the samples shows that the microorganisms did not suffer drastic changes between the different stages.

The samples from Stage I correspond to two periods of stabilization at different times. Even so, it can be observed that the four samples have a similarity percentage of $81.22 \%$. It can be inferred that the biological system of the Tamarindos recreational park does not show strong changes in its microbial population over time under normal operating conditions.
The Shannon-Weaver diversity index for each of the DGGE profiles was calculated using the GelCompar ${ }^{\circledR}$ II program (Applied Maths, Belgium). The results are shown in Table 4.

Table 4 Shannon-Weaver diversity index

\begin{tabular}{llll}
\hline Stage & & Rail & $\begin{array}{l}\text { S-W } \\
\text { Index }\end{array}$ \\
\hline \multirow{3}{*}{ Stage I } & Stabilization & 3 & 2,4776 \\
& & 4 & 2,4619 \\
& & 5 & 2,3255 \\
& & 6 & 2,4646 \\
\hline \multirow{2}{*}{ Stage II } & \multirow{2}{*}{$\mathrm{C}=300 \mu \mathrm{g} / \mathrm{L}$} & 7 & 2,9036 \\
& & 8 & 2,5007 \\
\hline \multirow{2}{*}{ Stage II } & \multirow{2}{*}{$\mathrm{C}=300 \mu \mathrm{g} / \mathrm{L}$} & 9 & 2,6952 \\
& & 10 & 2,6816 \\
\hline
\end{tabular}

The diversity indices are expressed from mathematical formulations that take into account three components of the structure of biotic communities such as wealth, equity and abundance. Wealth refers to the number of taxa determined in a sample, equity represents the uniformity in the distribution of individuals in the taxa, and abundance refers to the total number of individuals counted in a sample.

The numerical results of the Shannon-Weaver Index indicate that the MePB did not have a significant effect on aerobic sludge diversity as the pollutant load increased. On the contrary, an increase in diversity is observed for the stages when it is in contact with the MePB.

The percentage of similarity shown in Figure 6 between all the samples of the experiment was $48 \%$. This indicates a high variation between the first stabilization samples, 
and the last samples that are in contact with the MePB. However, considering the results of the Shannon-Weaver Diversity Index, the conditions of diversity over time were not disadvantaged. It is probably that the microbial populations that interact in the process are adapted, and those that are not are replaced by others that tolerate the conditions of the contaminant.

\section{Conclusions}

The SBR system is considered a functional technology for the removal of MePB and organic matter through aerobic biological activity, achieving removal efficiencies greater than $95 \%$ under optimal conditions.

Aerobic sludge is characterized by having a high richness and diversity of microorganisms. With the incorporation of MePB in biological environments, changes occur in microbial populations. However, diversity persists during the contact time at concentrations of 300 and 600 $\mu \mathrm{gMePB} / \mathrm{L}$, and the removal efficiency is not significantly affected.

The design conditions of a treatment system are established in stationary periods. An optimum sludge age must be maintained to reach high efficiencies. However, the dynamic behavior of microbial populations over time must be considered.

\section{Acknowledgments}

The authors would like to thank First Project Support Fund of Committee for the Development of Research (CODI) from the University of Antioquia for funding the project.

\section{References}

[1] Y. A. Londoño and G. A. Peñuela, "Biological removal of different concentrations of ibuprofen and methylparaben in a sequencing batch reactor (SBR)," Water, Air, Soil Pollut., vol. 226, no. 12, p. 393, Nov. 2015.

[2] M. Gros, M. Petrovic, and D. Barceló, "Analysis of emerging contaminants of municipal and industrial origin," in Emerging
Contaminants from Industrial and Municipal Waste: Occurrence, Analysis and Effects, D. Barceló and M. Petrovic, Eds. Heidelberg, Germany: Berlin, Heidelberg: Springer Berlin Heidelberg, 2008, pp. 37-104.

[3] E. N. Evgenidou, I. K. Konstantinou, and D. A. Lambropoulou, "Occurrence and removal of transformation products of PPCPs and illicit drugs in wastewaters: A review," Total Environ., vol. 505, Feb. 2015. [Online]. Available: https://doi.org/10.1016/j.scitotenv.2014. 10.021

[4] D. Bledzka, J. Gromadzińska, and W. Wasowicz, "Parabens. from environmental studies to human health," Environ. Int., vol. 67, Jun. 2014. [Online]. Available: https://doi.org/10.1016/j.envint.2014.02. 007

[5] M. Rodasa, L. A. Portugal, J. Avivar, J. M. Estela, and V. Cerdà, "Parabens determination in cosmetic and personal care products exploiting a multi-syringe chromatographic (MSC) system and chemiluminescent detection," Talanta, vol. 143, Oct. 2015. [Online]. Available: https://doi.org/10.1016/j.talanta.2015.04.055

[6] W. Li, Y. Shi, L. Gao, J. Liu, and Y. Cai, "Occurrence, fate and risk assessment of parabens and their chlorinated derivatives in an advanced wastewater treatment plant," J. Hazard. Mater., vol. 300 , Dec. 2015. [Online]. Available: https://doi.org/10.1016/j.jhazmat. 2015.06.060

[7] Y. A. Londoño, M. Muriel, N. L. Ospina, and G. Peñuela, "Implementation and automation of a sequencing batch reactor with a logo-oba6 programmable low-cost controller," Rev. Politec., vol. 10, pp. 95-103, 2014.

[8] Manual de laboratorio de Procesos Biológicos, Dirección de bienestar universitario y departamento de publicacione, medellin colombia, 2008.

[9] Standard Methods for the Examination of Water and Wastewater, American Public Health Association, American Water Works Association, Water Environment Federation, 2012.

[10] B. Blair, A. Nikolaus, C. Hedman, R. Klaper, and T. Grundl, "Evaluating the degradation, sorption, and negative mass balances of pharmaceuticals and personal care products during wastewater treatment," Chemosphere, vol. 134, pp. 395-401, Sep. 2015.

[11] R. Schwarzenbach, P. Gschwend, and D. Imboden, Enviromental organic chemistry, 2nd ed. Hoboken, USA: John Wiley \& Sons, Inc, 2003.

[12] A. J. et al., "Biological degradation of pharmaceuticals in municipal wastewater treatment: Proposing a classification scheme," Water Res., vol. 40, no. 8, May 2006. [Online]. Available: https://doi.org/10. 1016/j.jhazmat.2015.06.060

[13] G. Muyzer, E. C. de Waal, and A. G. Uitterlinden, "Profiling of complex microbial populations by denaturing gradient gel electrophoresis analysis of polymerase chain reaction-amplified genes coding for 16s rRNA," Appl. Environ. Microbiol, vol. 59, no. 3, pp. 695-700, Mar. 1993.

[14] N. C. et al., "Removal of ibuprofen and its transformation products: experimental and simulation studies," Sci. Total Environ., vol. 433, Sep. 2012. [Online]. Available: https://doi.org/10.1016/j.scitotenv. 2012.06.060

[15] J. F. Muñoz and M. Ramos, "Reactores discontinuos secuenciales: Una tecnología versátil en el tratamiento de aguas residuales," Cienc. Ing. Neogranad, vol. 24, no. 1, pp. 49-66, Jun. 2014. 